\title{
COMPARISON OF GENETIC EFFECTS OF SCATTERING RADIATION WITH DIRECT GAMMA RAYS IN THE STAMEN HAIRS OF TRADESCANTIA OHIENSIS KU 7 CLONE $^{1)}$
}

\author{
SADAO ICHIKAWA ${ }^{2)}$ \\ Laboratory of Genetics, Faculty of Agriculture, Kyoto University, \\ Sakyo-ku, Kyoto 606
}

Received October 11, 1972

Previous studies on somatic mutation rates in Tradescantia stamen hairs at low radiation levels, which were carried out at the gamma field of the National Institute of Radiation Breeding, suggested that scattering radiation from the gamma field might have had a genetical efficiency a few to several times higher than that of direct ${ }^{60} \mathrm{Co}$ gamma radiation (Ichikawa 1971, 1972b). If this turns out to be true, the safety standards which are presently applied to radiation facilities must be reconsidered because such standards have been established on the basis of regarding the biological and genetical effectiveness of scattering radiation to be at most equal to that of the primary direct radiation. The present experiment was carried out in order to confirm the previous results of a higher efficiency of scattering radiation.

\section{MATERIAL AND METHODS}

The material used in the present experiment was Tradescantia ohiensis Ref. KU 7 clone $(2 n=24$, a heterozygote for flower color), the same material as in the previous studies (Ichikawa 1971, 1972b), and the characteristics of this clone have been described in detail elsewhere (Ichikawa 1970, 1971).

Seven plants potted in $12 \mathrm{~cm}$ post, each having at least four young inflorescences of flowering size, were selected and six of them were exposed to ${ }^{60} \mathrm{Co}$ gamma rays and/or to scattering radiation, leaving the remaining one as control. The preparation of the plants and the irradiation treatments were performed at the National Institute of Radiation Breeding, Omiya, Ibaraki-ken. For the irradiation treatments, wooden poles were planted at adequate positions in the gamma fields, and on each pole a manually operated two-storey lift was installed. The potted plants were set on the lifts and were lifted to certain heights so that the plants set on the upper storey of

1) Contribution from the Laboratory of Genetics, Faculty of Agriculture, Kyoto University, No. 374.

2) Present address : Rama de Genética, Colegio de Postgraduados, ENA, Chapingo, México. 
the lifts are exposed only to scattering radiation while those on the lower storey to both direct gamma rays and scattering radiation (see Fig. 1). The heights above the ground level (of inflorescences) and the exposure rates at these positions are also shown in Fig. 1. The exposure rates were measured by Prof. H. Yamaguchi of the Laboratory of Radiation Genetics, University of Tokyo, Dr. A. Yamashita of the National Institute of Radiation Breeding, and their co-workers with a thermo-luminescence dosimeter during the experimental period. The irradiation of potted plants was started on September 10 and stopped on September 21, 1971, and an eight-day irradiation was conducted during the eleven-day period.

\begin{tabular}{|c|c|c|c|c|c|c|}
\hline \multirow[b]{2}{*}{ POSITION } & \multicolumn{3}{|c|}{ SCATTERING RADIATION } & \multicolumn{3}{|c|}{$\begin{array}{c}\text { DIRECT GAMMA RAYS } \\
\text { PLUS } \\
\text { SCATTERING RADIATION }\end{array}$} \\
\hline & A & B & c & D & $E$ & $\mathbf{F}$ \\
\hline $\begin{array}{l}\text { EXPOSURE RATE } \\
\text { (R/DAY) }\end{array}$ & 7.20 & 5.28 & 1.92 & $25 \cdot 2$ & 8.40 & 4.08 \\
\hline HEIGT (m) & 4.90 & 5.30 & 5.95 & 2.30 & 2.95 & 3.65 \\
\hline
\end{tabular}

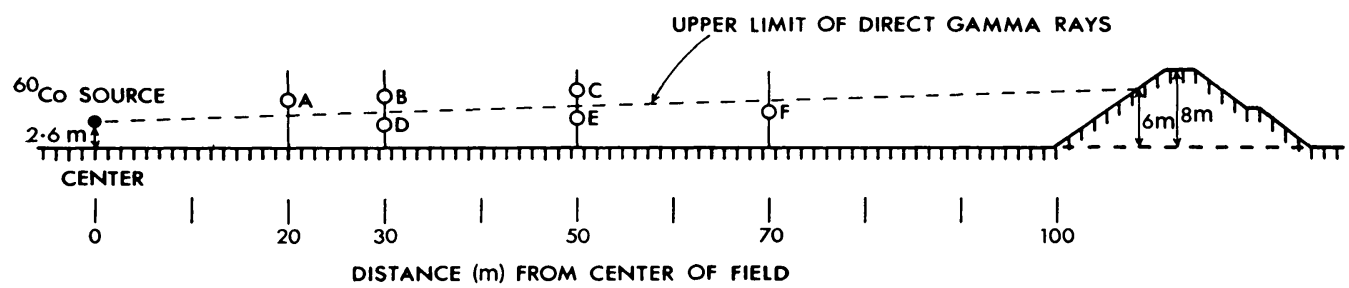

Fig. 1. Illustration of radiation treatments performed in the gamma field. Plants of Tradescantia ohiensis $\mathrm{KU} 7$ clone potted in $12 \mathrm{~cm}$ pots were lifted to positions $\mathrm{A}$ to $\mathrm{F}$. Plants lifted to $\mathrm{A}, \mathrm{B}$ and $\mathrm{C}$ were exposed to scattering radiation, and those lifted to $\mathrm{D}, \mathrm{E}$ and $\mathrm{F}$ to gamma rays and scattering radiation. Exposure rate and height of each position are indicated.

The irradiated and control bare-rooted plants were carried back to Kyoto on September 23 and were re-potted in $18 \mathrm{~cm}$ pots. Observation of the stamen hairs and scoring of induced mutations were carried out for 16 days after carrying the plants back to Kyoto. The maximum and minimum temperatures during the experimental period in Omiya were 28.5 and $12.0^{\circ} \mathrm{C}$, respectively, and those in Kyoto were 30.7 and $7.0^{\circ} \mathrm{C}$, respectively. Mean daily temperature ranged between 23.7 to $18.0^{\circ} \mathrm{C}$ in Omiya and between 25.2 to $14.7^{\circ} \mathrm{C}$ in Kyoto during the periods.

\section{RESULTS AND DISCUSSION}

Increase of somatic pink mutations in the stamen hairs of the irradiated plants were observed throughout the observation period. The frequency of pink mutations was especially higher during the period of September 29 to October 6. Thus the data 
taken on those days were pooled, and the calculation of somatic pink mutation frequency after each treatment was done based on the pooled data.

Somatic mutation frequency is expressed here as the average number of pink mutant events per stamen hair, as in the previous studies. A pink mutant event represents two or more contiguous pink cells or a single pink cell and is considered to have been derived from a mutation induced in a single meristematic hair cell (see Fig. 2 in Ichikawa 1972a).

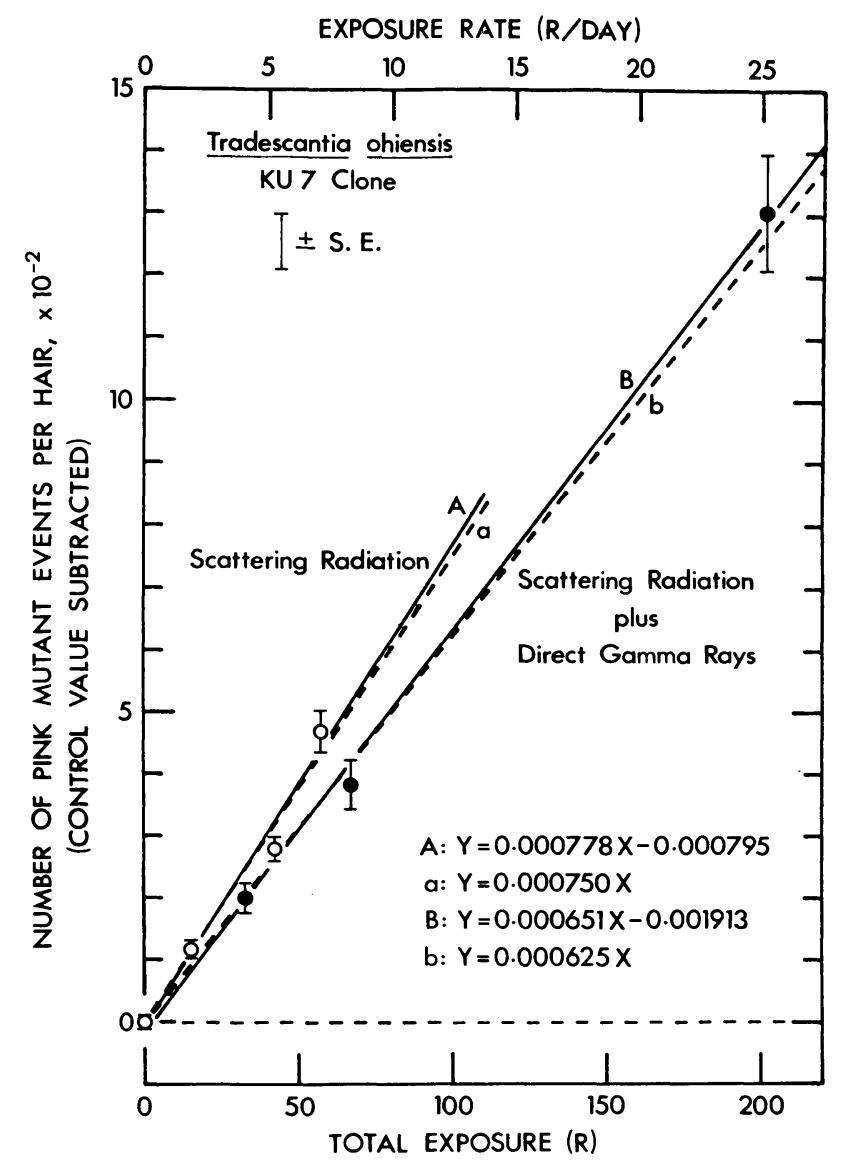

Fig. 2. Average numbers of pink mutant events per hair (minus control) plotted against total exposure and exposure rate. Open circles are the points obtained from plants exposed to scattering radiation, and solid circles from plants exposed to gamma rays plus scattering radiation. Lines drawn are the best-fit lines obtained with the least square method (solid lines, $\mathrm{A}$ and $\mathrm{B}$ ) and those through the origin obtained by calculating weighed average slopes (broken lines, $a$ and $b$ ).

The data collected are presented in Table 1 . When the data (minus control) are plotted against total exposure (daily exposure $\times 8$ ), it is seen that more somatic pink 
mutations were induced with scattering radiation than with direct gamma rays plus scattering radiation per unit exposure (Fig. 2). That means, scattering radiation has a greater genetic efficiency in inducing somatic mutations than direct gamma rays.

Table 1. Avarage numbers of pink mutant events per stamen hair after treatments with scattering radiation or with gamma rays plus scattering radiation

\begin{tabular}{|c|c|c|c|c|c|}
\hline $\begin{array}{l}\text { Exposure rate } \\
(\mathrm{R} / \mathrm{day})\end{array}$ & $\begin{array}{l}\text { Total } \\
\text { exposure } \\
(\mathrm{R})\end{array}$ & $\begin{array}{l}\text { No. of } \\
\text { hairs } \\
\text { examined }\end{array}$ & $\begin{array}{c}\text { No. of } \\
\text { pink } \\
\text { mutant events }\end{array}$ & $\begin{array}{l}\text { No. of pink } \\
\text { mutant events } \\
\text { per hair } \pm \text { S.E. }\end{array}$ & $\begin{array}{l}\text { Minus } \\
\text { control }\end{array}$ \\
\hline Control* & $0^{*}$ & 4,659 & 32 & $0.0069 \pm 0.0011$ & 0.0000 \\
\hline \multicolumn{6}{|c|}{ Scattering radiation } \\
\hline 1.92 & 15.4 & 4,328 & 80 & $0.0185 \pm 0.0015$ & 0.0116 \\
\hline 5.28 & 42.2 & 7,873 & 274 & $0.0348 \pm 0.0020$ & 0.0279 \\
\hline 7.20 & 57.6 & 8,315 & 447 & $0.0538 \pm 0.0033$ & 0.0469 \\
\hline \multicolumn{6}{|c|}{ Gamma rays plus scattering radiation } \\
\hline 4.08 & 32.6 & 5,258 & 141 & $0.0268 \pm 0.0024$ & 0.0199 \\
\hline 8.40 & 67.2 & 2,751 & 124 & $0.0451 \pm 0.0040$ & 0.0382 \\
\hline 25.2 & 201.6 & 2,556 & 351 & $0.1373 \pm 0.0094$ & 0.1304 \\
\hline
\end{tabular}

*Plant placed in a control field of the NIRB about $640 \mathrm{~m}$ apart from the center of the gamma field. Radiation level at this control field is about $0.05 \mathrm{mR} / \mathrm{hr}$, thus an about $8 \mathrm{mR}$ exposure is given to the control plant during the irradiation period.

Table 2. The exposure rates $(\mathrm{mR} / \mathrm{hr})$ measured simultaneously with the irradiation experiment*

\begin{tabular}{|c|c|c|c|c|}
\hline \multirow{2}{*}{ Radiation } & \multicolumn{4}{|c|}{ Distance $(\mathrm{m})$ from ${ }^{60} \mathrm{Co}$ Source } \\
\hline & 20 & 30 & 50 & 70 \\
\hline Scattering radiation & $360(\mathrm{~A})^{* *}$ & $264(\mathrm{~B}) * *$ & $96(\mathrm{C}) * *$ & $42(3 \mathrm{~m}$ above $\mathrm{F})$ \\
\hline $\begin{array}{l}\text { Gamma rays plus } \\
\text { scattering radiation }\end{array}$ & - & $1260(\mathrm{D})^{* *}$ & $420(\mathrm{E})^{* *}$ & $204(\mathrm{~F})^{* *}$ \\
\hline \multicolumn{5}{|c|}{$\begin{array}{l}\text { *Measured with a thermo-luminescence dosimeter by Prof. H. Yamaguchi, Dr. A. Yamashita } \\
\text { and their co-workers. } \\
\text { **Positions shown in Fig. } 1 .\end{array}$} \\
\hline \multicolumn{5}{|c|}{$\begin{array}{l}\text { Table 3. Calculated exposures }(\mathrm{R}) \text { of scattering radiation and of } \\
\text { gamma rays at positions } \mathrm{D}, \mathrm{E} \text { and } \mathrm{F}\end{array}$} \\
\hline \multirow{2}{*}{\multicolumn{2}{|c|}{ Radiation }} & \multicolumn{3}{|c|}{ Position } \\
\hline & & $\mathrm{D}$ & $\mathrm{E}$ & $\mathrm{F}$ \\
\hline \multicolumn{2}{|c|}{$\begin{array}{l}\text { Gamma rays plus scattering } \\
\text { radiation (Total exposure) }\end{array}$} & 201.6 & 67.2 & 32.6 \\
\hline \multicolumn{2}{|l|}{ Scattering radiation } & 42.2 & 15.4 & 6.7 \\
\hline \multicolumn{2}{|l|}{ Gamma rays } & 159.4 & 51.8 & 25.9 \\
\hline
\end{tabular}

*Positions shown in Fig. 1.

**Based on the data in Table 2. Twenty-hour irradiation per day and eight-day irradiation. 
Table 4. Calculated mutation frequencies (number of pink mutant events per hair) due to scattering radiation and to gamma rays at positions $\mathrm{D}, \mathrm{E}$ and $\mathrm{F}$

\begin{tabular}{lccc}
\hline \hline \multirow{2}{*}{ Category } & \multicolumn{3}{c}{ Position* } \\
\cline { 2 - 4 } & $\mathrm{D}$ & $\mathrm{E}$ & $\mathrm{F}$ \\
\hline Mutation rate observed (minus control) & 0.1304 & 0.0382 & 0.0199 \\
Mutation rate by scattering radiation & 0.0317 & 0.0116 & 0.0050 \\
Mutation rate by gamma rays & 0.0987 & 0.0266 & 0.0149 \\
\hline
\end{tabular}

*Positions shown in Fig. 1 .

In Fig. 2, the best-fit lines obtained with the least square method (solid lines) and those through the origin, the point for control, obtained after calculation of weighed average slopes (broken lines) are drawn. The slopes of these best-fit lines obtained with two different methods are very close to each other, i.e., $7.78 \times 10^{-4}$ and $7.50 \times 10^{-4}$ for scattering radiation alone and $6.51 \times 10^{-4}$ and $6.25 \times 10^{-4}$ for direct gamma rays plus scattering radiation.

In order to know the relative genetical efficiency of scattering radiation as compared with direct ${ }^{60} \mathrm{Co}$ gamma rays, the following calculations were made based on the results of the dosimetry (Table 2) carried out simultaneously with the present irradiation experiment. Assuming that the exposure rates of scattering radiation at positions $\mathrm{D}$, $\mathrm{E}$ and $\mathrm{F}$ were equal to those at positions $\mathrm{B}, \mathrm{C}$ and $3 \mathrm{~m}$ above $\mathrm{F}$ (see Fig. 1), respectively, it is possible to calculate the accumulated exposures of direct gamma rays and those of scattering radiation separately as shown in Table 3. Using the calculated exposure data for scattering radiation and also using the formula of $\mathrm{Y}=0.000750 \mathrm{X}$ shown in Fig. 2, mutation frequencies due to scattering radiation can be obtained as shown in Table 4. Deduction of these frequencies from observed frequencies gives mutation frequencies by direct gamma rays alone (Table 4). Based on the resultant values, a formula, $\mathrm{Y}=0.000591 \mathrm{X}$, is calculated for direct gamma rays. Comparing the slope of this formula, 0.000591 , with the slope of 0.000750 for scattering radiation, it can be said that scattering radiation is about $27 \%$ more efficient than direct gamma rays in inducing somatic mutations.

When the other formula of $\mathrm{Y}=0.000778 \mathrm{X}-0.000795$ for scattering radiation is used for calculation instead of $\mathrm{Y}=0.000750 \mathrm{X}$ used above, $\mathrm{Y}=0.000621 \mathrm{X}-0.001585$ is obtained as the formula for direct gamma rays. Thus, in this case, the slopes indicate an about $25 \%$ higher efficiency of scattering radiation as compared with direct gamma rays.

Previous studies suggested that scattering radiation might have had a few to several times higher efficiency than direct ${ }^{60} \mathrm{Co}$ gamma rays in inducing pink mutations in the stamen hairs of KU 7 clone of Tradescantia (Ichikawa 1971, 1972b). The present study confirms the higher efficiency of scattering radiation, but its relative efficiency is determined to be about 1.27 or 1.25 , putting the efficiency of direct gamma rays as 1. The present results with scattering radiation were obtained by treating the plants 
at the positions 20,30 or $50 \mathrm{~m}$ apart from the ${ }^{60} \mathrm{Co}$ source, while the previous results of the effects of scattering radiation were taken from the plants placed on the top of the protection earth bank 111.5m apart from the source (Ichikawa 1971, 1972b). Therefore, there might be a qualitative difference of scattering radiation such as a difference of encrgy which might affect the genetic responses.

At any rate, it seems to be certain that scattering radiation from the gamma field with a ${ }^{60} \mathrm{Co}$ source has a higher genetic effect than the direct gamma rays. It should be emphasized here that the present results were obtained with Tradescantia stamen hairs, the biological system with which we can detect the genetic effects of radiations very sensitively and precisely even in the range of doses as low as those expressed in millirads (Mericle and Mericle 1965; Ichikawa 1972b; Sparrow et al. 1972).

\section{SUMMARY}

Potted plants of Tradescantia ohiensis KU 7 clone (heterozygous for flower color) were exposed to ${ }^{60} \mathrm{Co}$ gamma rays and/or scattering radiation in the gamma field of the National Institute of Radiation Breeding. Somatic mutation rates were scored in the stamen hairs for 16 days, and the genetic effects of direct gamma rays and scattering radiation were compared. Scattering radiation was proved to be about 27 or $25 \%$ more efficient in inducing somatic mutations than the direct gamma rays from ${ }^{60} \mathrm{Co}$ source.

\section{ACKNOWLEDGMENTS}

The author wishes to express his sincere thanks to Prof. H. Yamaguchi of the University of Tokyo and to Dr. A. Yamashita of the National Institute of Radiation Breeding for their kindly co-operation for the present study. He also wishes to acknowledge the assistance of the personnel of the National Institute of Radiation Breeding in performing the radiation treatments.

\section{LITERATURE CITED}

Ichikawa, S., 1970 Relative biological efficiency of $14.1 \mathrm{MeV}$ fast neutrons and ${ }^{137} \mathrm{Cs}$ gamma rays in the stamen hairs of Tradescantia reflexa Rafin. Japan. J. Genetics 45: 205-216.

Ichikawa, S., 1971 Somatic mutation rate at low levels of chronic gamma-ray exposures in Tradescantia stamen hairs. Japan. J. Genetics 46: 371-381.

Ichikawa, S., 1972a Radiosensitivity of a triploid clone of Tradescantia determined in its stamen hairs. Radiation Botany 12: 179-189.

Ichikawa, S., 1972b Somatic mutation rate in Tradescantia stamen hairs at low radiation levels: Finding of low doubling doses of mutations. Japan. J. Genetics 47: in press.

Mericle, L. W., and R. P. Mericle, 1965 Biological discrimination of differences in natural background radiation level. Radiation Botany 5: 475-492.

Sparrow, A. H., A. G. Underbrink, and H. H. Rossi, 1972 Mutations induced in Tradescantia by small doses of X-rays and netrons: Analysis of dose-response curve. Science 176: 916-918. 